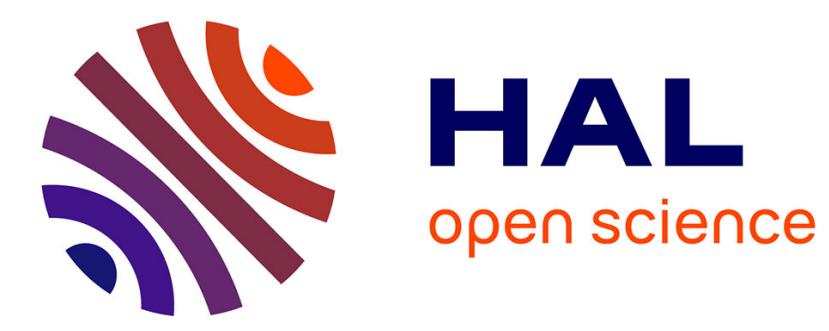

\title{
5-FU-induced neurotoxicity in cancer patients with profound DPD deficiency syndrome: a report of two cases
}

Pierre-Yves Cordier, André Nau, Joseph Ciccolini, Manuela Oliver, Cédric Mercier, Bruno Lacarelle, Eric Peytel

\section{To cite this version:}

Pierre-Yves Cordier, André Nau, Joseph Ciccolini, Manuela Oliver, Cédric Mercier, et al.. 5-FUinduced neurotoxicity in cancer patients with profound DPD deficiency syndrome: a report of two cases. Cancer Chemotherapy and Pharmacology, 2011, 68 (3), pp.823-826. 10.1007/s00280-011-16660. hal-00695369

\section{HAL Id: hal-00695369 https://hal.science/hal-00695369}

Submitted on 8 May 2012

HAL is a multi-disciplinary open access archive for the deposit and dissemination of scientific research documents, whether they are published or not. The documents may come from teaching and research institutions in France or abroad, or from public or private research centers.
L'archive ouverte pluridisciplinaire HAL, est destinée au dépôt et à la diffusion de documents scientifiques de niveau recherche, publiés ou non, émanant des établissements d'enseignement et de recherche français ou étrangers, des laboratoires publics ou privés. 


\section{5-FU-INDUCED NEUROTOXICITY IN CANCER PATIENTS WITH PROFOUND DPD DEFICIENCY SYNDROME: A REPORT OF TWO CASES.}

Pierre-Yves Cordier ${ }^{1 *}$, André $\mathrm{Nau}^{1}$, Joseph Ciccolini ${ }^{2}$, Manuela Oliver ${ }^{1}$, Cédric Mercier $^{2}$, Bruno Lacarelle ${ }^{2}$, Eric Peytel ${ }^{1}$.

${ }^{1}$ : Hôpital d'Instruction des Armées Laveran, 13998 Marseille, France

2 : Laboratoire de Pharmacocinétique, CHU Timone, 13385 Marseille, France

* : corresponding author: pierre-yves.cordier@laposte.net 


\section{Abstract}

Purpose: 5-fluorouracil (5-FU) is a mainstay for treating various solid tumors in adults, including digestive and head and neck cancers. 5-FU-related toxicities usually include haematological, digestive and cutaneous features. Additionally, 5-FU has been described as being potentially neurotoxic in patients, but these side effects are quite rare in clinical practice. Here we report two cases of sudden and unpredictable drug-induced neurotoxicities that occurred in patients undergoing their first course of 5-FU-based chemotherapy. Patients \& Methods: None of these patients had any previous neurological disorder history, and both were treated following standard regimen (LV-5-FU2 and TPF for patient 1 and 2, respectively). Neurotoxicity included drowsiness, acute confusion plus dysarthria for the first patient, and seizure, confusion and signs of metabolic encephalopathy for the second one. In addition, typical 5-FU-related severe toxicities (e.g., neutropenia, mucosities) were observed. Both patients slowly recovered from these neurologic toxicities under supportive treatment. It was assumed that overexposure to 5-FU could explain the severe toxicities encountered. To test this hypothesis, we retrospectively evaluated the dihydropyrimidine dehydrogenase (DPD) activity of these patients on a phenotypic basis. Results: Evaluation of the uracil to di-hydrouracil (U/UH2) ratio in plasma revealed a profound DPD deficiency syndrome in both patients. Conclusion: These cases suggest that 5-FU standard dosage administration may lead to strong overexposure, responsible for the severe toxicities observed, including the neurological features. It implies that DPD-deficiency can cause neurotoxicity in 5-FUtreated patients, and advocates for the prospective screening of DPD deficiency 
before starting any 5-FU-containing chemotherapy so as to prevent such side effects in the future.

\section{Keywords}

5-fluorouracil - dihydropyrimidine dehydrogenase deficiency - neurotoxicity encephalopathy - hypothyroidism 


\section{Introduction}

5-FU remains one of the most prescribed anticancer drugs worldwide, with an estimated number of $2.10^{6}$ new patients treated each year, mostly as part of combination therapies. Like most other cytotoxics, 5-FU-related side effects include digestive and haematological toxicities. Admittedly, 10 to $25 \%$ of patients will experience severe toxicities upon 5 -FU intake, including $0.5-3 \%$ of toxic-deaths, depending on the regimen [1,2]. The intensity of 5-FU-induced toxicities can dramatically increase to become life-threatening in patients with DPD deficiency. This pharmacogenetic syndrome results in a partial or complete loss of their ability to detoxify fluoropyrimidine derivatives in the liver $[3,4]$. Although DPD deficiency is a contra-indication for the administration of full dose 5-FU or oral capecitabine, prospective screening of DPD status prior to treatment is still not officially recommended by health authorities like the F.D.A. in the U.S. or the E.M.E.A. in Europe, as it can be for other pharmacogenetic syndromes having an impact on the disposition of cytotoxics like UGT1A1 (irinotecan) and TPMT (6-mercaptopurine). Consequently, today most patients are administered with standard dosage of 5-FU, regardless of their DPD status. Retrospective studies have demonstrated that $70 \%$ of the severe toxicities and $80 \%$ of the toxic deaths could be related to functional DPD deficiency, and therefore could be prevented by prospective screening and development of DPD-based dose tailoring strategies [5]. Beside haematological toxicities, some drug-induced neurotoxicities have been described with 5-FU, although this latter are by far less frequent and usually are not dose limiting [6]. It has been recently suggested that such neurotoxicities could be associated with deregulation in TYMS, another pharmacogenomic syndrome linked with outburst of 
severe toxicities with 5-FU [7]. To date, little relationships have been evidenced between DPD deficiency and increased risk of developing neurotoxicity in patients undergoing 5-FU treatment [8].

\section{Case-Reports}

We report the cases of two patients treated at Laveran Military Hospital of Marseille, France, in 2008 and 2009. Patients characteristics are given in Table 1. Patient 1 was a 65 year old woman hospitalized for a sigmoid carcinoma revealed by an occlusive syndrome. After surgical treatment by colostomy and secondary laparoscopic sigmoidectomy, she was given LV-5-FU2 (total 5-FU dose: $6400 \mathrm{mg}$ ) as a standard adjuvant setting. Eleven days after 5-FU administration, the patient came back to the hospital with grade-4 mucosities (standard CTCAE grading) and several skin toxicities (hands, breast, face) that started at home on the third day after the end of the chemotherapy. She also presented biological signs of haematologic toxicity like grade-4 neutropenia (543 neutrophils per $\mathrm{mm}^{3}$ ) and grade-2 thrombocytopenia $\left(60.10^{3}\right.$ platelets per $\left.\mathrm{mm}^{3}\right)$. Conservative treatment, granulocyte growth factors and parenteral nutrition were undertaken and allowed the patient to recover quickly. However, grade-3 neurologic disorders gradually happened, such as drowsiness, confusion and dysarthria. Electroencephalogram revealed diffuse cerebral suffering without any epileptic discharge. Brain CT scan and MRI, as well as cerebrospinal fluid (CSF) analysis were normal (data not shown). Neurologic disorders spontaneously decreased after several weeks, except for a persistent frontal lobe syndrome with cognitive and behavorial features. Forthcoming administrations of 5FU courses were cancelled, and patient's DPD status was retrospectively checked, 
based upon the use of the canonical determination of the $\mathrm{U} / \mathrm{UH} 2$ ratio in plasma [2]. Briefly, $500 \mu \mathrm{l}$ plasma were extracted using liquid-liquid procedure with ether/isopropanol. Supernatant was dried under nitrogen, reconstituted into mobile phase and injected into a 1100 HPLC-UV system (Agilent, France) equipped with a RP18 $250 \times 4.5 \mathrm{~mm} 5 \mu \mathrm{m}$ column (XTerra, Waters, France) eluted with a pH3, $5 \mathrm{mM}$ $\mathrm{KH}_{2} \mathrm{PO}_{4}$ buffer pumped at a $0.6 \mathrm{ml} / \mathrm{min}$ flow rate. UV detection was set at $210 \mathrm{~nm}$. Data were acquired using the Chemstation software (Agilent, France). Using this methodology, we found that this patient was profoundly DPD-deficient (Figure 1), with a $\mathrm{U} / \mathrm{UH} 2$ ratio value of 3.6, i.e. more than 3-time higher than the mean values usually recorded in our reference population [5]. Owing to the severity of her DPD deficiency, treatment was definitively stopped.

Patient 2 was a 55 year old man treated with a TPF protocol for a head and neck cancer scheduled as following: docetaxel (D1), cisplatin (D1) plus continuous 5-FU infusion (D1-D4, total dose $6150 \mathrm{mg}$ ). Immediate tolerance to the treatment was excellent. However, the patient suddenly presented grade-4 neurotoxicity starting on D5 (i.e., convulsive seizures associated with persisting loss of consciousness). The patient was then transferred to intensive care unit (I.C.U.), where orotracheal intubation and mechanical ventilation were undertaken. Physical examination did not show any focal neurologic sign, and pupils were equal and reactive to light. Biological analysis, cerebral CT scan and cerebrospinal fluid analysis were normal. Electroencephalogram showed slow and unresponsive brain activity, suggesting metabolic encephalopathy (Figure 2). While in the ICU, the patient developed a grade-4 neutropenia with sepsis. With the use of probabilistic antibiotherapy, growth factor administration and supportive treatment, he fully recovered from both his 
neurologic and haematological toxicities after 7 days. DPD status was retrospectively checked, based upon the use of the U/UH2 ratio determination in plasma by HPLCUV, as described previously. As for patient 1, we found that this patient was deeply DPD-deficient $(\mathrm{U} / \mathrm{UH} 2=5.6$, i.e. 4-times higher than the mean values of the reference population, Figure 1). Further use of 5-FU was excluded, and the patient was next scheduled for a docetaxel + cisplatin only protocol.

\section{Discussion.}

In cancer patients, central nervous system (CNS) disorders can have many origins like cerebral metastasis, carcinomatous meningitis or paraneoplastic syndromes [6]. Such manifestations can also be induced by anti-cancer treatments like surgery, radiotherapy or chemotherapy. Although occasionally described in the literature, neurotoxicity is rarely dose limiting with 5-FU, as it can be for other cytotoxic drugs like oxaliplatin. To date, little is known about the biochemical or pharmacological basis for such side effects. The combination with leucovorin, which proved to be neurotoxic by itself, could trigger the neurological disorders observed in individuals

undergoing a fluoropyrimidine-based therapy [9]. Additionally, 5-FU-induced thiamine deficiency could have caused the cerebellar ataxia reported in some other patients [10]. This latter hypothesis is supported by the successful management of 5-FUinduced encephalopathy by thiamine infusion, as reported by various groups $[11,12]$. However, because here, at least partial spontaneous recovery was observed in both cases, the actual role thiamine administration had played in the recovery of patients described in the past with 5-FU-induced neurological disorders can be questioned. Here, we report two cases of severe CNS toxicities that occurred after the first course 
of standard 5-FU-containing regimen. This led to the cancellation of further 5-FUbased treatment, with selection for other treatment modalities or complete stop of the chemotherapy. These toxicities were unpredictable because none of these patients had previously experienced such neurological features. In both patients, canonical side effects usually related to 5-FU (e.g., neutropenia, skin toxicity, mucosities) were observed as well. Because of the severity of these latter toxicities, we hypothesized that DPD deficiency could have caused the unusual neurotoxicity we observed. DPD deficiency is known to alter 5-FU pharmacokinetic profile in individuals given full dosage, with subsequent higher risk to experience severe or lethal toxicities upon drug intake. To test this hypothesis, we evaluated the DPD status in these patients. Here, we based our DPD evaluation on a simple and rapid functional testing which clinical relevance had already been demonstrated $[5,13]$. Several other functional approaches (e.g., uracil breath test, uracil challenge test, to name but a few) to establish the DPD status in patients had been proposed in the literature, with similar benefit compared to genotypic-based techniques [2,14]. After phenotypic investigations, both patients proved to be severely DPD deficient (Figure 3), thus strongly suggesting that overexposure to 5 -FU had caused the severe toxicities we observed, much probably including the neurologic ones. Recent treatment with a full dose of 5-FU and proven severe DPD-deficiency, were the only common points for these two patients. Additionally, it has to be underlined that both patients suffered from hypothyroidism, successfully treated by substitutive therapy. However, based upon our current knowledge of 5-FU pharmacology and pharmacokinetics, it is unlikely that this condition could be at the origin of the severe neurotoxicity the patients had experienced. However, the repeated occurrence of similar cases in the future may lead this hypothesis to be reconsidered. Overall, the present clinical 
observations, although concerning only two patients, indicate that DPD-deficiency can be responsible for severe neurotoxicity in 5-FU-treated patients, even if no neurological predisposition is known. Prospective screening for DPD deficiency could help to reduce the risk of developing such side effects in the future.

\section{References.}

1. Tsalic M, Bar-Sela G, Beny A, Visel B, Haim N (2003) Severe toxicity related to the 5-fluorouracil/leucovorin combination (the Mayo Clinic regimen): a prospective study in colorectal cancer patients. Am J Clin Oncol 26 (1):103-106

2. Mercier C, Ciccolini J (2006) Profiling dihydropyrimidine dehydrogenase deficiency in patients with cancer undergoing 5-fluorouracil/capecitabine therapy. Clin Colorectal Cancer 6 (4):288-296

3. Lee A, Ezzeldin H, Fourie J, Diasio R (2004) Dihydropyrimidine dehydrogenase deficiency: impact of pharmacogenetics on 5-fluorouracil therapy. Clin Adv Hematol Oncol 2 (8):527-532

4. van Kuilenburg ABP (2006) Screening for dihydropyrimidine dehydrogenase deficiency: to do or not to do, that's the question. Cancer Invest 24 (2):215-217

5. Ciccolini J, Mercier C, Evrard A, Dahan L, Boyer J-C, Duffaud F, Richard K, Blanquicett C, Milano G, Blesius A, Durand A, Seitz J-F, Favre R, Lacarelle B (2006) A rapid and inexpensive method for anticipating severe toxicity to fluorouracil and fluorouracil-based chemotherapy. Ther Drug Monit 28 (5):678-685

6. Guilloton L, Michaud A, Potier V, Le Berre J, Drouet A, Felten D (2005) Ataxia and confusion after treatment with 5 Fluorouracile. Rev Med Interne 26 (12):986-987 
7. Kim S-R, Park C-H, Park S, Park J-O, Lee J, Lee S-Y (2010) Genetic polymorphisms associated with 5-Fluorouracil-induced neurotoxicity. Chemotherapy $56(4): 313-317$

8. Takimoto $\mathrm{CH}$, Lu ZH, Zhang R, Liang MD, Larson LV, Cantilena LR, Grem JL, Allegra CJ, Diasio RB, Chu E (1996) Severe neurotoxicity following 5-fluorouracilbased chemotherapy in a patient with dihydropyrimidine dehydrogenase deficiency. Clin Cancer Res 2 (3):477-481

9. Meropol NJ, Creaven PJ, Petrelli NJ, White RM, Arbuck SG (1995) Seizures associated with leucovorin administration in cancer patients. J Natl Cancer Inst 87 (1):56-58

10. Aksoy M, Basu TK, Brient J, Dickerson JW (1980) Thiamin status of patients treated with drug combinations containing 5-fluorouracil. Eur J Cancer 16 (8):10411045

11. Kwon KA, Kwon H-C, Kim MC, Kim S-H, Oh SY, Lee S, Kim H-J (2010) A case of 5-Fluorouracil induced encephalopathy. Cancer Res Treat 42 (2):118-120

12. Cho IJ, Chang HJ, Lee KE, Won HS, Choi MY, Nam EM, Mun Y-C, Lee SN, Seong C-M (2009) A case of Wernicke's encephalopathy following fluorouracil-based chemotherapy. J Korean Med Sci 24 (4):747-750

13. Yang CG, Ciccolini J, Blesius A, Dahan L, Bagarry-Liegey D, Brunet C, Varoquaux A, Frances N, Marouani H, Giovanni A, Ferri-Dessens R-M, Chefrour M, Favre R, Duffaud F, Seitz J-F, Zanaret M, Lacarelle B, Mercier C (2011) DPD-based adaptive dosing of 5-FU in patients with head and neck cancer: impact on treatment efficacy and toxicity. Cancer Chemother Pharmacol 67 (1):49-56 
14. Ciccolini J, Gross E, Dahan L, Lacarelle B, Mercier C (2010) Routine dihydropyrimidine dehydrogenase testing for anticipating 5 -fluorouracil-related severe toxicities: hype or hope? Clin Colorectal Cancer 9 (4):224-228

Table 1. Patient 1 and Patient 2 characteristics. *: TPF: taxol $\left(75 \mathrm{mg} / \mathrm{m}^{2}\right.$ D1) + cisplatin $\left(75 \mathrm{mg} / \mathrm{m}^{2} \mathrm{D} 1\right)+5$-FU $\left(750 \mathrm{mg} / \mathrm{m}^{2} / \mathrm{d}\right.$ D1-D4), ${ }^{* *}$ : NCI CTCAE V 4.02, ${ }^{* \star *}$ : ICU: Intensive Care Unit, ${ }^{* * * *}$ : EEG: electroencephalogram.

PATIENT 1

Female, 65 years

Sigmoid

Oesophagus

\begin{tabular}{|c|c|c|}
\hline Cancer & Sigmoid & Oesophagus \\
\hline Regimen & LV-5-FU2 & $\mathrm{TPF}^{*}$ \\
\hline Total 5-FU dose (mg) & 6400 & 6150 \\
\hline $\begin{array}{l}\text { Non neurological } \\
\text { toxicities }\end{array}$ & $\begin{array}{c}\text { Skin, grade- } 4^{\star *} \\
\text { mucosities, grade-3 } \\
\text { neutropenia, grade-2 } \\
\text { thrombopenia }\end{array}$ & $\begin{array}{l}\text { Grade-4 neutropenia, + } \\
\text { sepsis }\end{array}$ \\
\hline Symptomatic care & $\begin{array}{l}\text { Parenteral nutrition, } \\
\text { Growth factors }\end{array}$ & $\begin{array}{l}\text { Stay in ICU } \mathrm{IC}^{\star * *} \text {, Growth } \\
\text { Factors, Antibiotherapy }\end{array}$ \\
\hline Neurological toxicities & $\begin{array}{c}\text { Drowsiness, Confusion, } \\
\text { Dysarthria (grade-3) }\end{array}$ & $\begin{array}{l}\text { Convulsions, Loss of } \\
\text { consciousness (grade- } 4 \text { ) }\end{array}$ \\
\hline Imagery & Normal & $\begin{array}{c}E E G^{* * * *} \text { : Signs for } \\
\text { metabolic encephalopathy }\end{array}$ \\
\hline Neurological Recovery & $\begin{array}{l}\text { Spontaneous, except from } \\
\text { persistent frontal lobe } \\
\text { syndrome }\end{array}$ & Full and spontaneous \\
\hline
\end{tabular}


Figure 1.

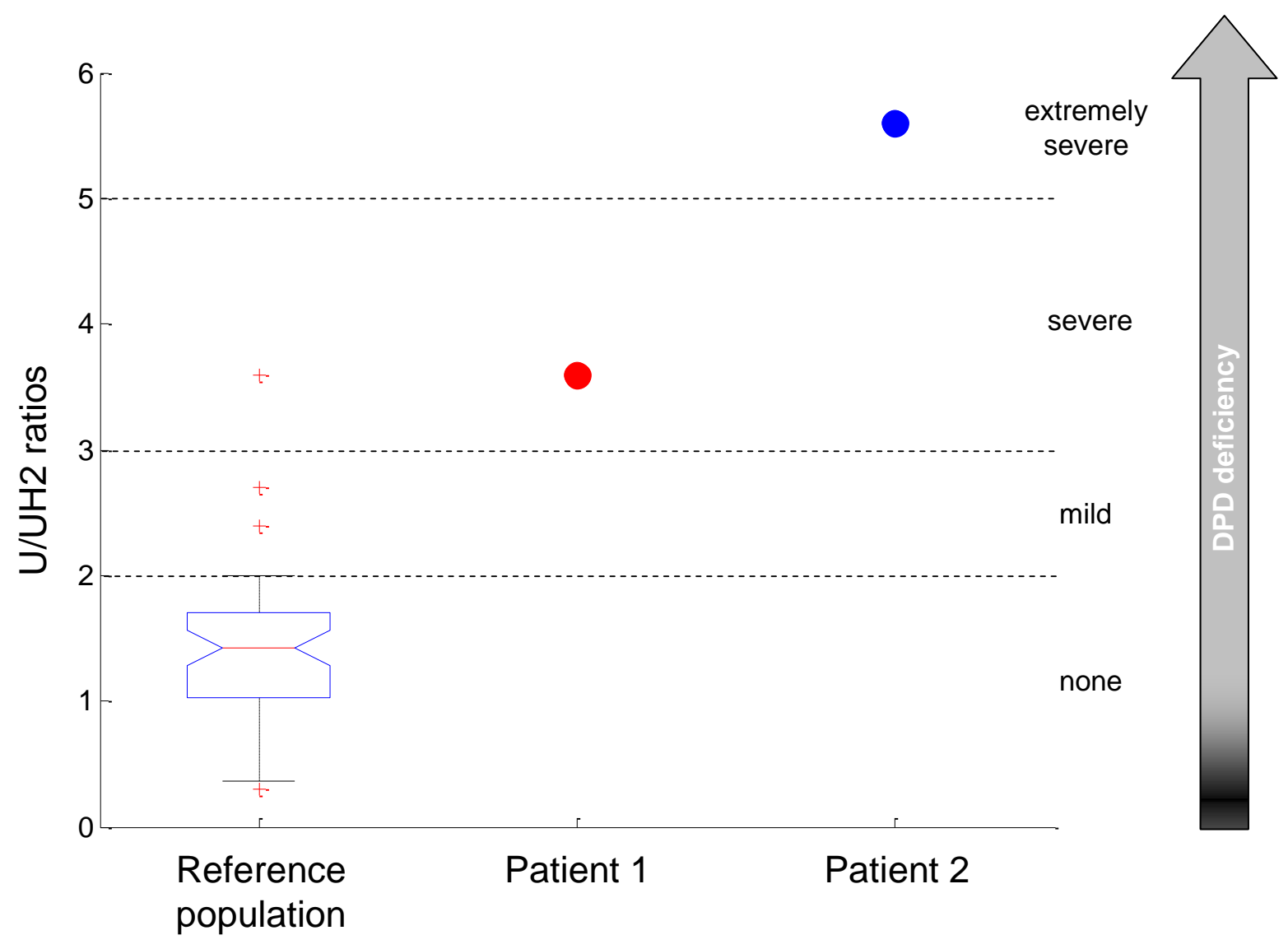


Figure 2.

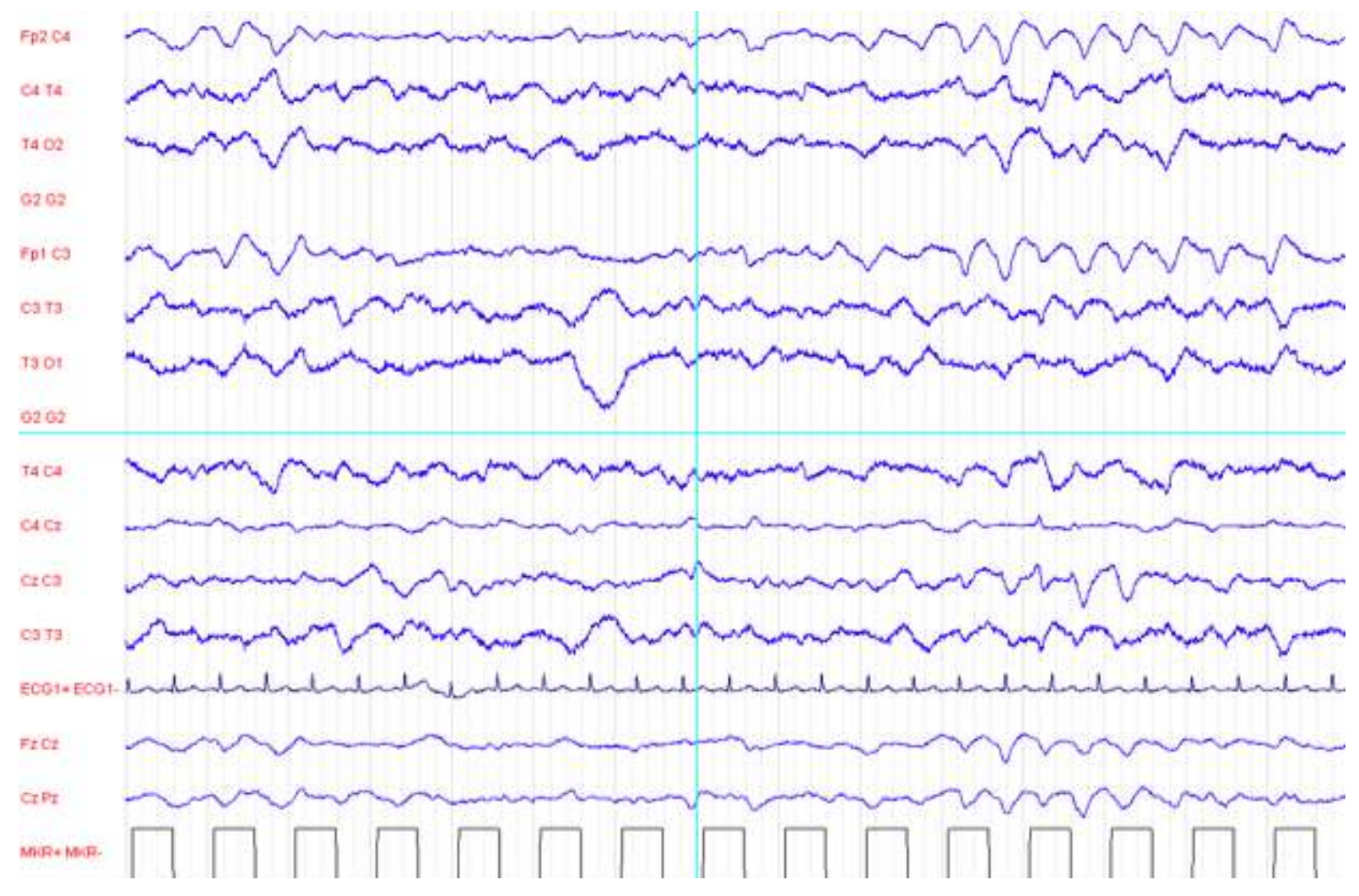


Figure 1: DPD status of Patient 1 and Patient 2, as evaluated following the U/UH2 ratio HPLC method in plasma. Both patients were found to be profoundly DPDdeficient with regard to our reference population [5].

Figure 2: Patient 2 electroencephalogram: slow and unresponsive activity with delta waves, suggesting metabolic encephalopathy. 